\title{
Atlas multimedia del Centro Histórico del Distrito Central de Honduras. Fase 2. La cartografía multimedia y su uso para el patrimonio histórico
}

\author{
Lilliam Sofía Gómez Solórzano
}

\section{Resumen}

Como partida inicial de este artículo se tomará el Atlas multimedia del Centro Histórico del Distrito Central de Honduras (ACHDC) (Gómez, Pineda, 2010), un hiperdocumento elaborado en una primera fase, que muestra la dimensión espacio-temporal del Centro Histórico del Distrito Central, sintetizando de manera digital la información y permitiendo visualizar los fenómenos histórico-patrimoniales, utilizando las Tecnologías de la Información Geográfica. Este hiperdocumento consta de pantallas digitales que resumen cada uno de los períodos históricos en que se conformaron las ciudades de Tegucigalpa y Comayagüela, que juntas forman el Distrito Central de Honduras, haciendo énfasis en las edificaciones de valor histórico y su traza urbana (plazas, calles, edificios), que definen el centro histórico de la ciudad. Este producto muestra a través de elementos multimedia: mapas, texto, fotografías e imágenes, que junto con el hipertexto y la referencia espacial de un mapa, dan como resultado productos de cartografía multimedia, en soportes no convencionales que van desde un CD hasta los mapas publicados en la web. En esta fase, el hiperdocumento pretende ser comprobado, frente a productos menos interactivos, con soportes convencionales como el papel. El uso se comprueba por medio de aplicaciones a posibles usuarios, tanto del producto de cartografía multimedia ACHDC, como un producto menos interactivo en soporte convencional, en donde ambos contienen la misma información, y así comprobar si la cartografía multimedia, con alto nivel de interactividad, es útil como medio de comunicación del patrimonio histórico cultural de una ciudad o si los soportes convencionales son más ventajosos, con el fin de comunicar al usuario el valor que tiene el centro histórico dentro de una ciudad. Posteriormente, pensar en diseñarlo centrándose en el usuario.

Palabras clave: Cartografía multimedia. Centro Histórico. Distrito Central de Honduras. Patrimonio histórico cultural. 


\section{INTRODUCCIÓN}

Las nuevas tecnologías computacionales de las últimas décadas ofrecen nuevas formas de soportes y de representación para la cartografía, haciendo de esta un elemento mucho más vivo e interactivo que los soportes convencionales como el papel. Para el caso de la representación de elementos que representan el patrimonio cultural de un lugar específico, el uso de la cartografía multimedia ha sido muy beneficioso, ya que provee componentes (video, audio, objetos en 3D, narraciones, etc.), que hacen despertar la creatividad del usuario a niveles superiores y que además son muy útiles para representar los fenómenos histórico patrimoniales de forma espacial (Gómez, 2010). En este artículo se pretende mostrar el uso de la cartografía para la representación de estos fenómenos en dos momentos, ambos pretenden mostrar la evolución espacial del centro histórico de Tegucigalpa y sus edificaciones de mayor importancia, pero en distintos soportes: uno en papel o tradicional, y otro en forma digital o multimedia. Estos dos atlas se han desarrollado a manera de prototipos y la investigación pretende mostrar cuál de los dos tipos ofrece una mejor visualización de estos fenómenos, aplicando pruebas a posibles usuarios del atlas.

\section{MARCO CONCEPTUAL}

\section{La cartografía multimedia}

El comienzo de la multimedia interactiva se le atribuye al Profesor Vanaveer Bush del MIT en 1930s, quien pretendía crear una máquina que sirviera para guardar y devolver información. El concepto de multimedia fue primeramente utilizado para referirse al despliegue de imágenes descritas por una voz grabada. Posteriormente, se introducen los conceptos de multimedia interactiva e hipermedia para referirse a los elementos de la media combinados con estructuras interactivas (Cartwright, 2010). Como elementos de la multimedia encontramos los siguientes: texto, audio, gráficos, animación y video. Esta se puede definir como la interacción con múltiples formas de comunicación utilizando como medio una computadora, es en realidad una forma de comunicación. Gracias al avance tecnológico de las últimas décadas es posible romper muchas barreras en la comunicación y en el acceso a la información, incluyendo en esta a la información geográfica. Es por ello que en la actualidad el acceso a la información geográfica o espacial no está solamente limitado a los profesionales dedicados a ese campo, esta se abre al usuario común, por medio de la creación de productos geográficos y cartográficos que se difunden de diversas formas (web, DVD, etc.), y que por ser diseñados para 
este usuario buscan ser más intuitivos y menos complicados que los programas específicos para profesionales.

La cartografía multimedia es la combinación de mapas con multimedia (Peterson, 1999). La multimedia es quien ofrece la habilidad para crear mapas distintos a los que ya estamos acostumbrados a ver, con nuevos niveles de interacción (Cartwright, 1994). Esto se refiere a botones y puntos dentro del espacio geográfico virtual (plano de la realidad geográfica) que dan acceso a nueva información, esa información geográfica se adapta también a nuevos aparatos de uso común: teléfonos, computadoras, televisión, películas, etc.

La multimedia surge de dos conceptos iniciales, el hipertexto y la hipermedia. El hipertexto es término introducido en 1965 por Ted Nelson, gurú de las computadoras. Inicialmente fue la forma más usada de hipermedia. Es un texto que permite a los lectores escoger y moverse dentro de la publicación siguiendo su propio patrón, no es lineal, los libros electrónicos son un ejemplo de esto (Raper, 1991). La hipermedia es una extensión del hipertexto a través del uso de la multimedia. Gráficos, sonido, animación y video (Jiang et al., 1995).

El uso de la multimedia se comienza a explotar con el aparecimiento del CD-ROM en 1982. Después de su aparecimiento comienzan a elaborarse los primeros productos cartográficos, así como también juegos geográficos. En la actualidad la multimedia es un fenómeno predominantemente online. Con esto nace un nuevo concepto, el hipermapa.

El hipermapa es un concepto que se introduce en 1990 por Laurini y Millert-Raffort, es visto como una manera de combinar multimedia con la geografía. Este concepto es el que da como nacimiento a la cartografía multimedia como una combinación de mapas con elementos media como texto, imágenes, fotos, video, etc. Algunos autores opinan que este concepto ha traído conceptos análogos a una revolución para el mundo de la cartografía, en el cual hace 500 años atrás era imposible duplicar mapas en papel y ahora con el internet eso es algo muy fácil (Cartwright, 2010).

Este tipo de cartografía es muy útil para los procesos democráticos donde todos deben de participar y debe de ser un producto de uso sencillo. Por esta razón, a la hora de realizar un mapa multimedia es preciso realizar pruebas a los posibles usuarios. Primeramente se desarrolla un prototipo y luego se aplican pruebas, posteriormente el diseño se mejora de acuerdo a las pruebas realizadas. 
Entre los ejemplos más importantes de cartografía multimedia podemos encontrar: el atlas de Canadá, el atlas de Suiza, el atlas de Antártica.

El primero fue uno de los que se realizó realizando un modelo hipermedia, que consiste en un esquema o flujograma que muestra como el atlas funcionaría, y que fue el primero en utilizar el proceso User Centred Design (UCD), que es un diseño centrado en el usuario, en el que a través de pruebas se optimiza el producto. Este UCD, ayuda a definir el público, el presupuesto, la funcionalidad, y a eliminar lo que no es útil en un producto de cartografía multimedia, presentando una metodología UCD (Cartwright, 2010).

Figura 1. Proceso User Centred Design (UCD), utilizado para el atlas de Canadá.

\section{Multimedia Cartography, 2010}

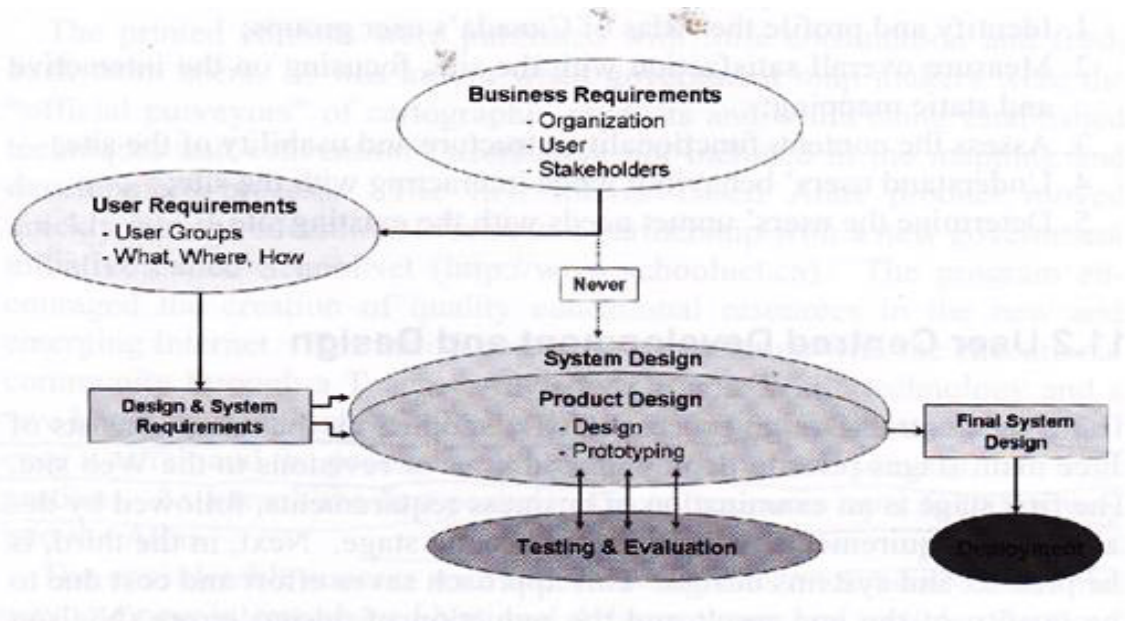

Este atlas también ha tenido muchas versiones, ya que se viene mejorando desde 1906, en que su soporte era papel.

La metodología anteriormente mencionada se aplica como investigación, buscando el atributo de satisfacción en el usuario, en donde se califica el porcentaje de satisfacción del producto en sus distintas ediciones: satisfacción interactiva, la información que tiene, el porcentaje de recomendación a terceros, y el porcentaje de usuarios que se animan a probar por primera vez el producto multimedia. El UCD abarca el diseño de la interface del usuario y las herramientas de la interface.

Con lo que respecta al atlas de Suiza, también fue diseñado pensando en el usuario, introduciendo un nuevo término Graphical User Interface (GUI) o inter- 
face gráfica del usuario, la cual es diseñada para el usuario, además que introduce nuevos elementos multimedia: 3D y vistas panorámicas, líneas del tiempo y alta calidad gráfica.

En el caso del atlas de antártica da inicio al geotagging, un proceso en el cual se asignan coordenadas geográficas a un sitio web, también utiliza el UCD, e introduce el Users Needs Analysis (UNA). Incorpora sonido, música, y la tecnología multi sensorial.

Como podemos ver la cartografía multimedia ofrece mayor interacción y medios que la tradicional, que es estática y aislada. Además de que ofrece una mayor representación de elementos cronológicos, por su capacidad de presentar elementos animados. Es por ello que se ha utilizado mucho, en los últimos años, para la representación del patrimonio histórico/ cultural de una región, donde organizaciones públicas como museos, gobiernos y comunidades la explotan para preservar digitalmente su patrimonio cultural (Adabala, 2010). Por la cantidad de medios que tiene para representar claramente esto: video, imagen, narración, etc.

Figura 2. Vista de un elemento multimedia utilizado para representar el patrimonio cultural de la zona de Andal en India. (Abadala, 2010)

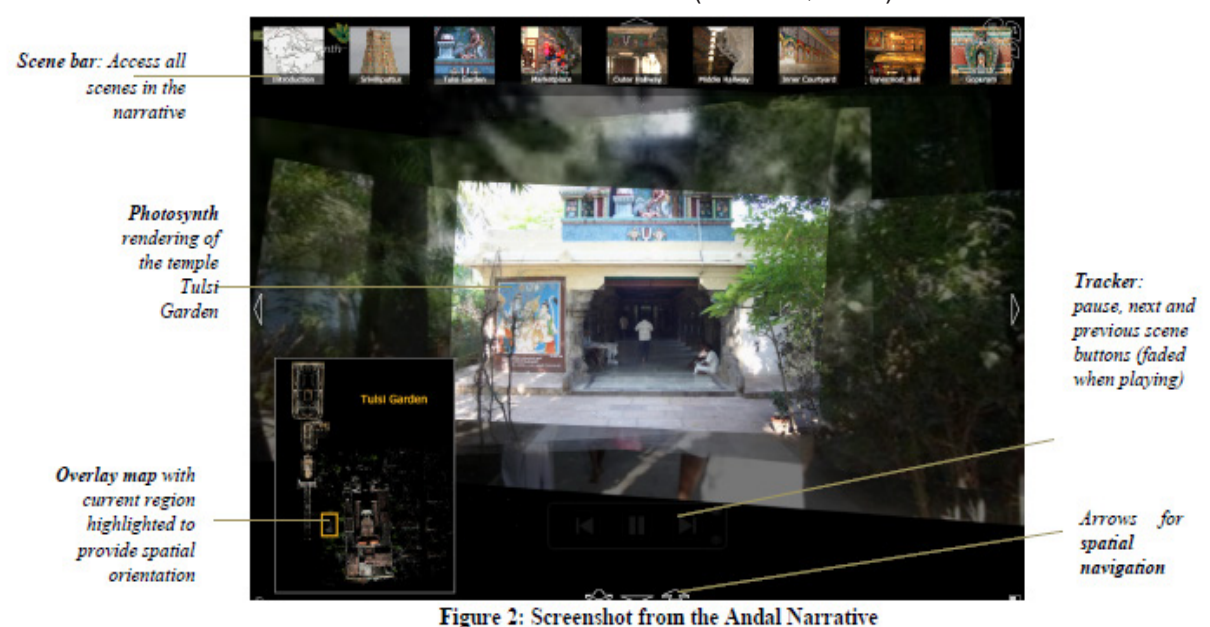

Los elementos más importantes en cartografía son: arte, ciencia y tecnología (Cartwright, 2010). En donde la ciencia se ocupa de corregir y perfeccionar los productos, la tecnología los produce y los distribuye, y el arte es la cara pública de la cartografía. 


\section{Atlas multimedia del Centro Histórico del Distrito Central de Honduras}

El Atlas multimedia del Centro Histórico del Distrito Central de Honduras es un producto multimedia realizado para mostrar la dimensión espacio-temporal del Centro Histórico del Distrito Central de Honduras y que sintetiza de manera digital la información permitiendo visualizar los fenómenos histórico-patrimoniales de forma espacial utilizando las Tecnologías de la Información Geográfica. Este fue creado utilizando una metodología basada en los modelos hipermedia, que incorporan el hipertexto y la multimedia, las cuales crean un hiperdocumento, al cual si le agregamos la referencia espacial creamos un hipermapa.

\section{METODOLOGÍA PARA LA CREACIÓN DELACHDC}

La metodología utilizada consistió en las siguientes cinco fases, como se muestra en la siguiente imagen.

Figura 3. Metodología utilizada para la creación del atlas del CHDC

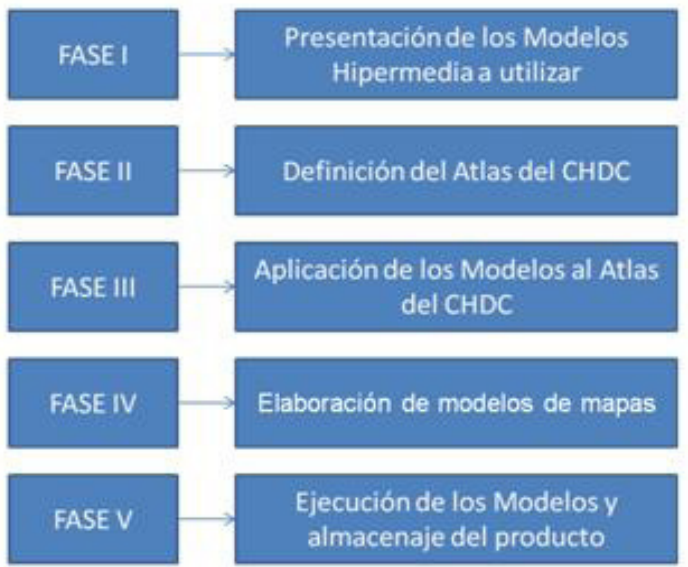

En la Fase I se presentan los cuatro modelos hipermedia que se utilizaron para crear la estructura del atlas del CHDC: Modelo de información, modelo de presentación, modelo de sincronización, modelo de navegación. 
Figura 4. Fase I de la metodología para el atlas CHDC

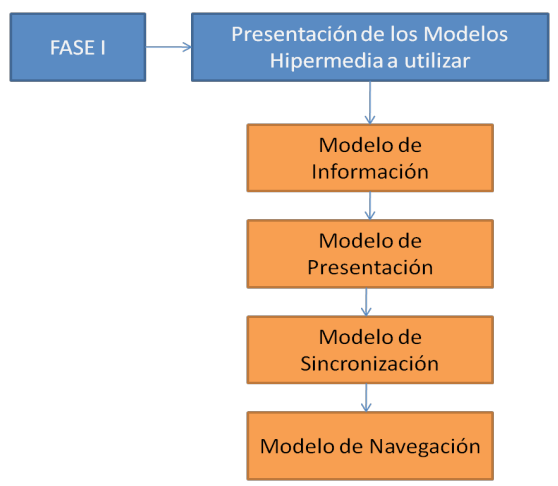

Figura 5. Modelo de información ACHDC

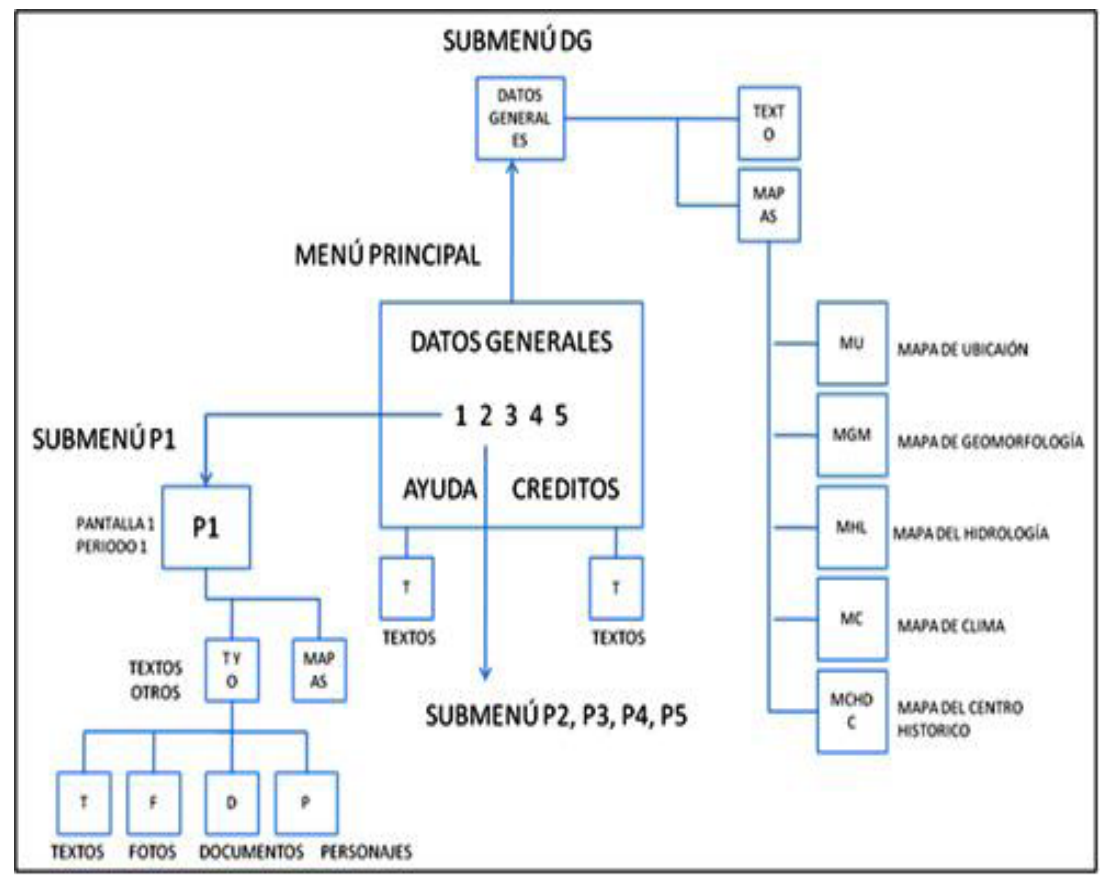


Figura 6. Modelos de presentación de todas las pantallas del atlas en conjunto

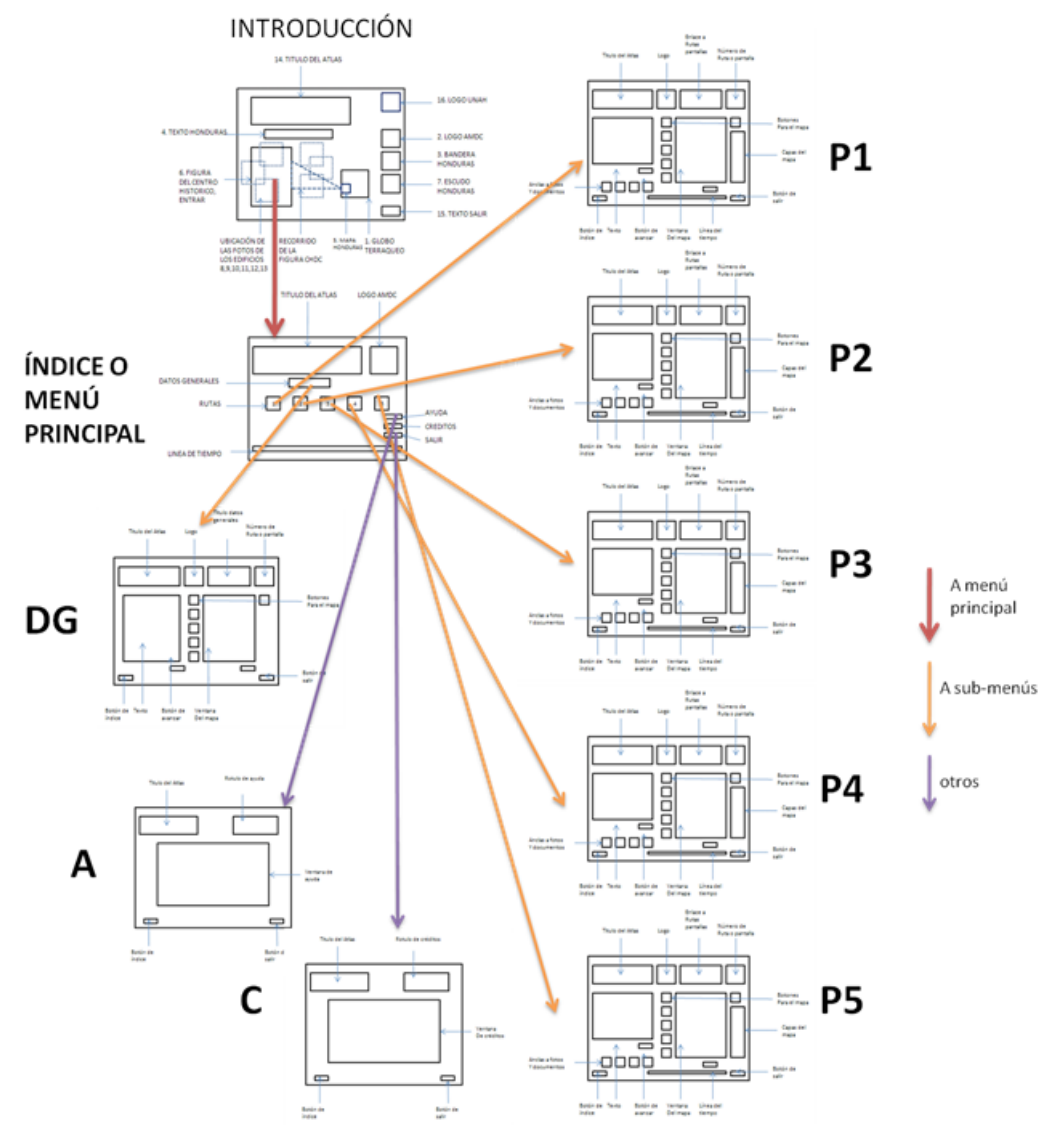

En la fase II se presenta el atlas, sus objetivos y propuesta, así como el público al cual se dirige. En esta fase se pretendió definir qué es lo que se quiere lograr. 
Figura 7. Fase II de la metodología para el atlas CHDC

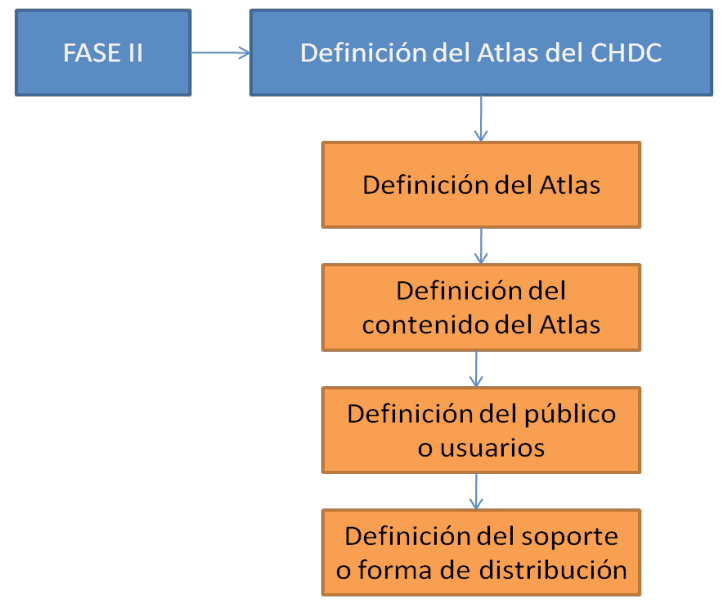

En la fase III se aplicaron los modelos hipermedia al atlas del CHDC dando como resultado un diagrama y grafos.

En la fase IV se elaboraron esquemas de mapas de cada período basándose en los archivos, mapas y demás información estudiada.

Figura 8. Fase IV de la metodología para el atlas CHDC

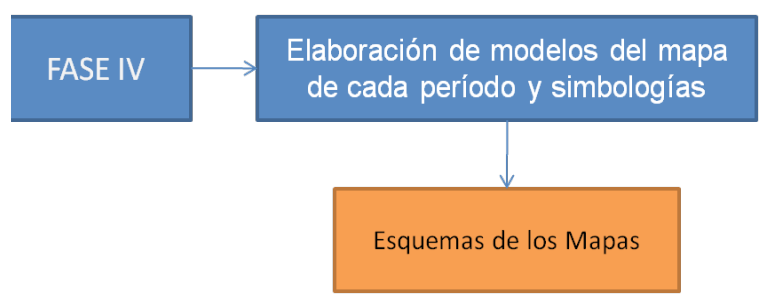

En la fase $V$ se refiere a los programas y medios de almacenaje, en los que los modelos hipermedia se ejecutaron para crear el producto 0 atlas del CHDC. Programas que permiten realizar los objetivos del atlas. 
Figura 9. Fase V de la metodología para el atlas del CHDC

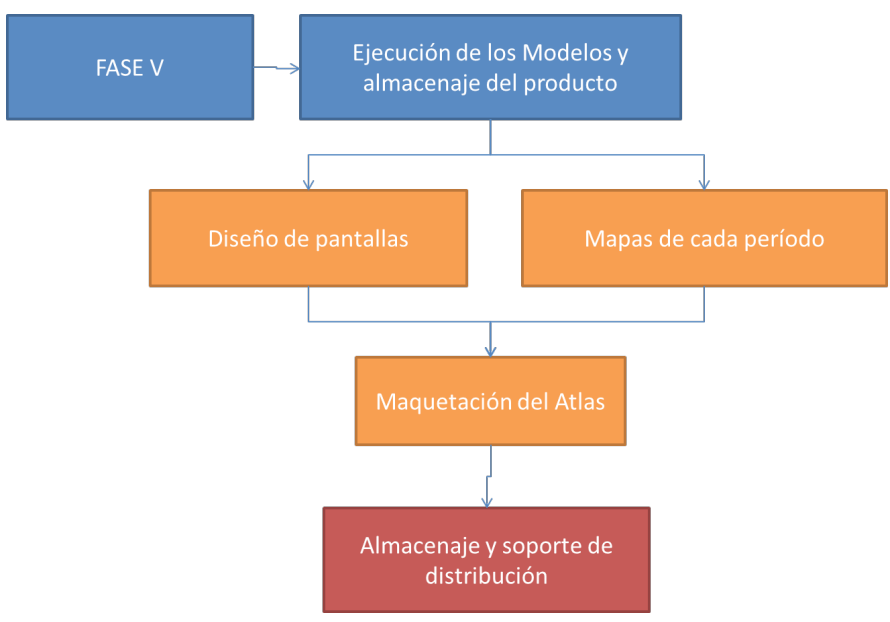

En cada una de estas fases se desarrollaron las actividades y se obtuvieron resultados.

\section{Productos finales del ACHDC de manera digital}

Los productos finales del atlas electrónico se muestran a continuación. El diseño está compuesto por diez pantallas, de las cuales hay cinco que están dedicadas a los períodos históricos, una de introducción, otra de índice, otra de datos generales, una de ayuda y una de créditos. 
Figura 10. Estructura general del atlas con las imágenes de los productos de las pantallas de los períodos históricos

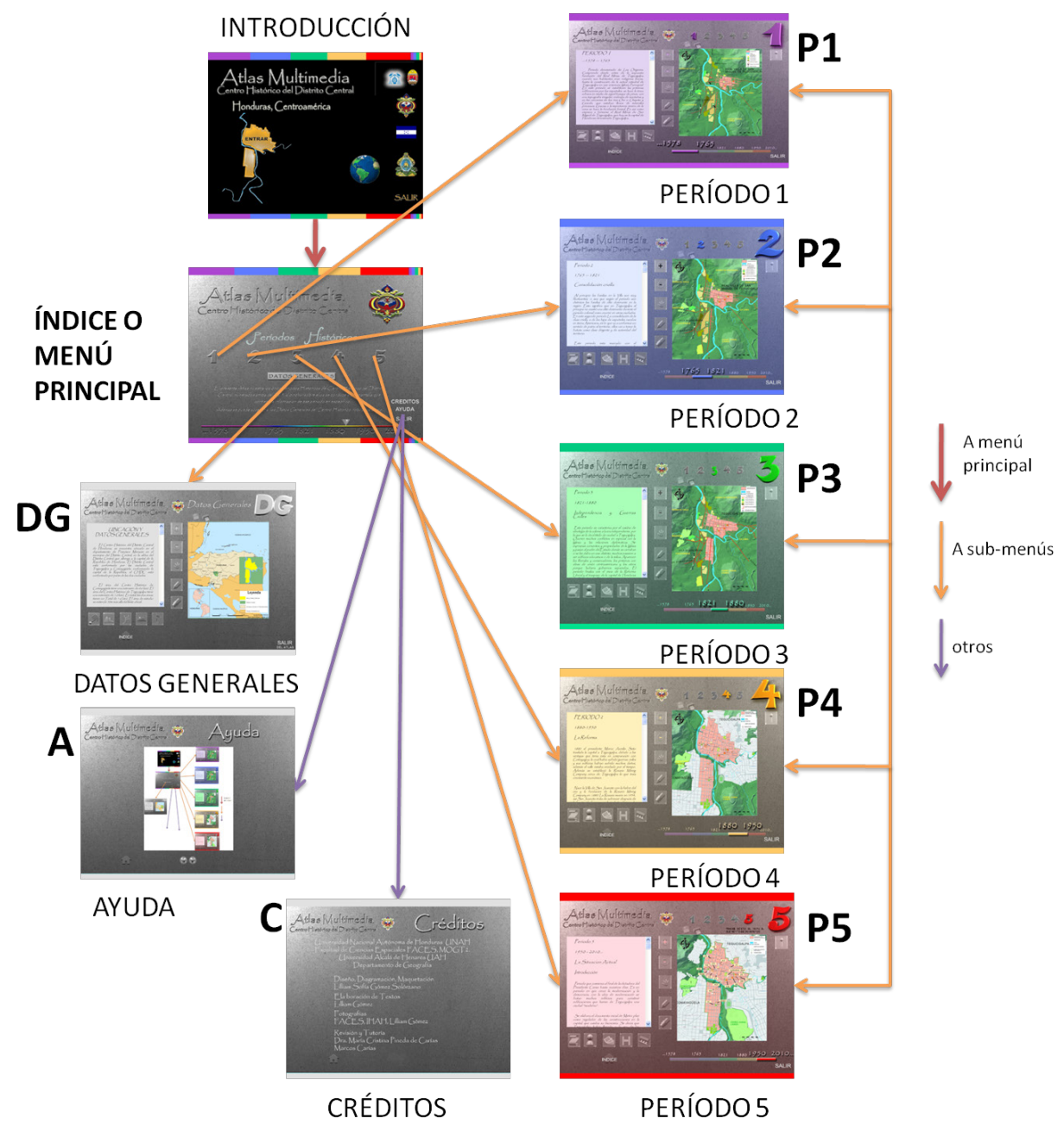




\section{Edificios históricos de importancia}

Algunos de los edificios más importantes del Centro Histórico se dibujaron en perspectiva axonométrica con un programa tipo vector, basándose en fotografías y planos del IHAH, para posteriormente colocarlos sobre el mapa del CHDC. En este caso ponemos como ejemplo a la catedral San Miguel Arcángel, construida en 1765 para sustituir a la primera parroquia que se incendió en 1746 (era de madera). La catedral San Miguel Arcángel fue la iglesia parroquial por varios siglos, es de importancia porque su construcción marca el período 2.

Figura 11. Catedral San Miguel Arcángel

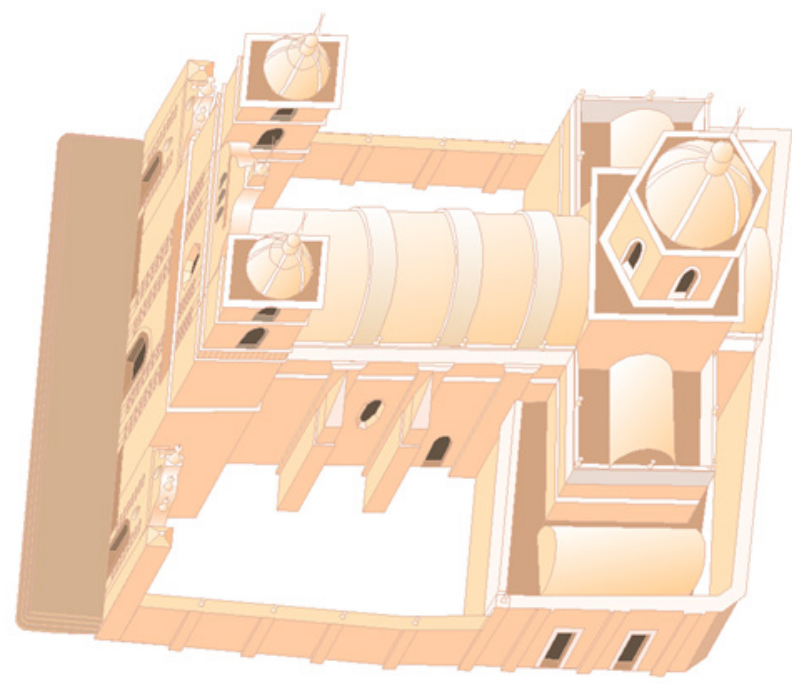

Fuente: Elaboración propia 
Figura 12. Pantalla y sus diferentes elementos y medios interactivos

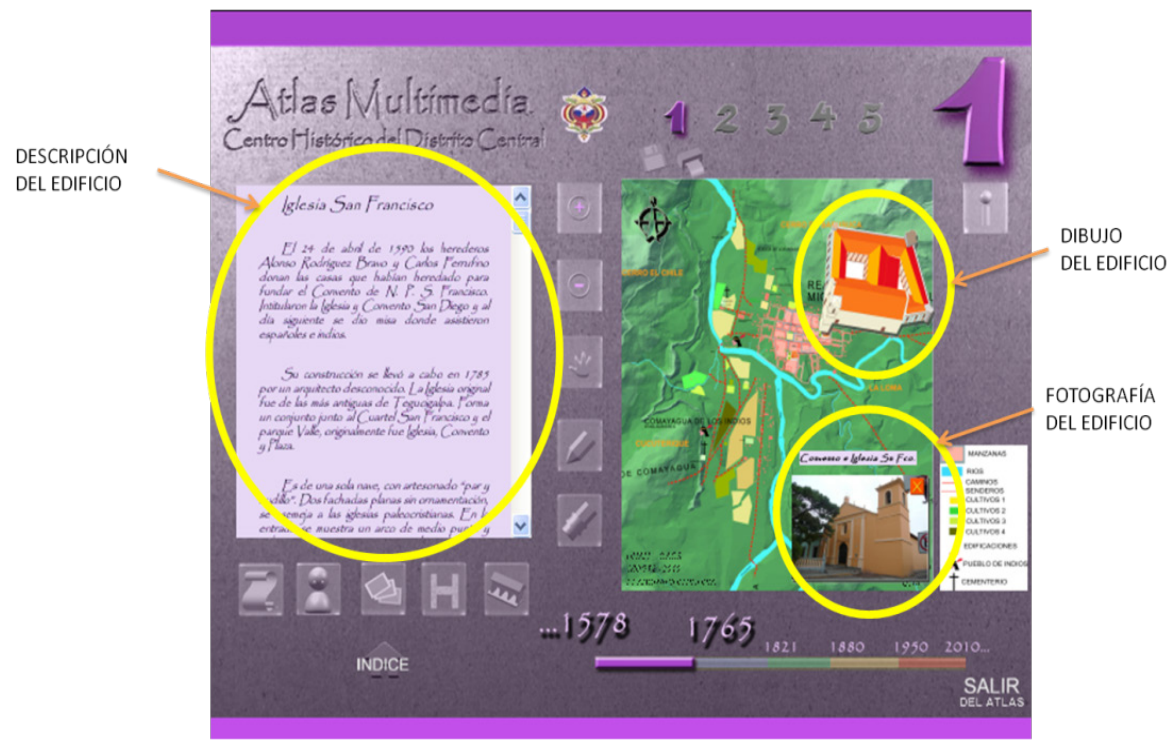

\section{El atlas del Centro Histórico versión papel}

El atlas en versión papel se realizó siguiendo un modelo de información parecido al del digital. Este contiene las siguientes partes: una portada, un índice, páginas que explican los datos generales del territorio, un bloque de páginas por período histórico (son cinco en total), referencias bibliográficas. Tiene un total aproximado de 200 páginas y está elaborado a manera de prototipo. 
Figura 13. Ejemplo de una de las páginas del ACHDC soporte papel

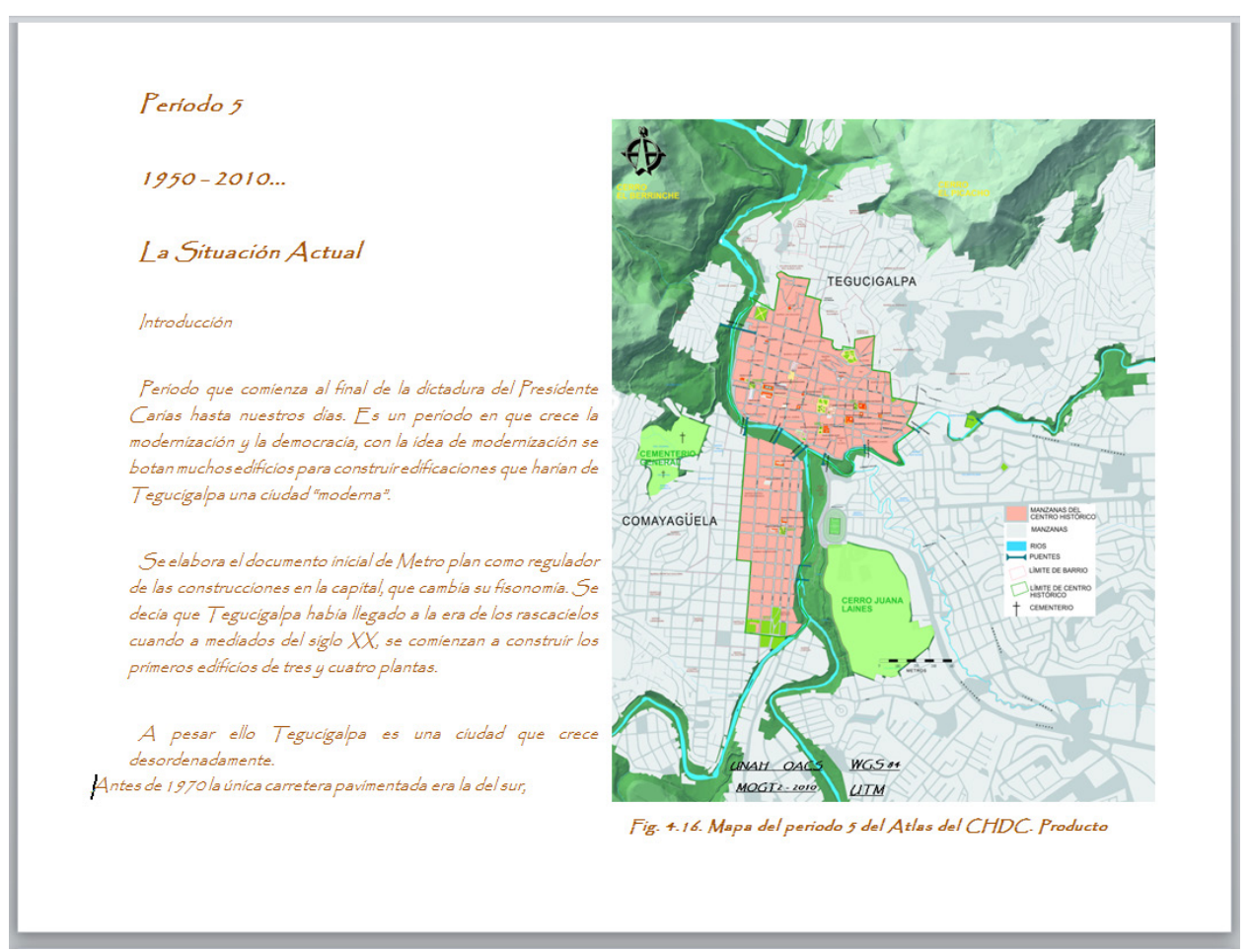

Fuente: Elaboración propia.

Figura 14. Modelo para la creación del ACHDC papel
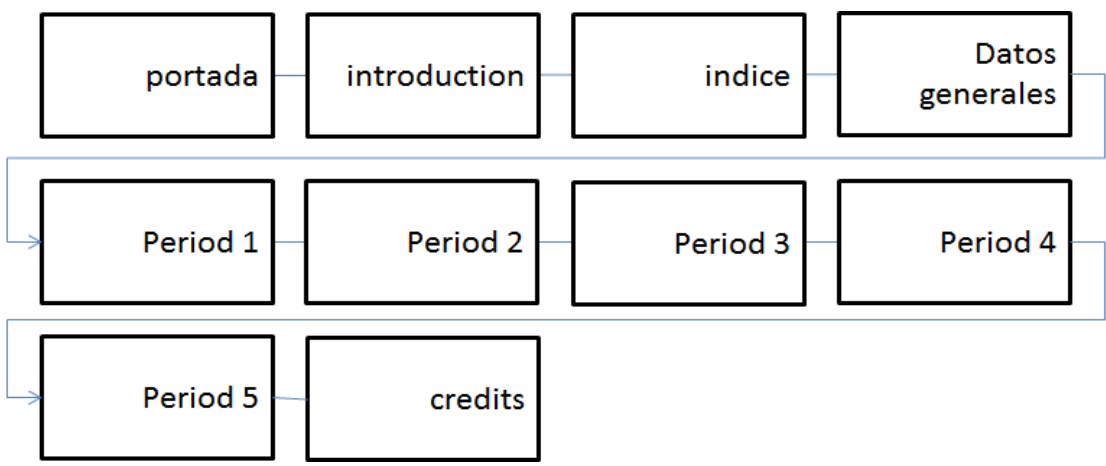

Fuente: Elaboración propia. 


\section{METODOLOGÍA}

Como se mencionó la metodología a utilizar es la aplicación de ambos instrumentos a posibles usuarios (en este caso, un público amplio). Durante la prueba se analizaran cuestiones con primera impresión de la persona, si comprende o le es fácil comenzar a explorar la información, posteriormente se aplicará una entrevista en la que el propio usuario responde el grado de satisfacción que ha tenido con cada uno de los productos.

\section{Figura 15. Modelo de entrevista}

\section{ENTREVISTA AL USUARIO}

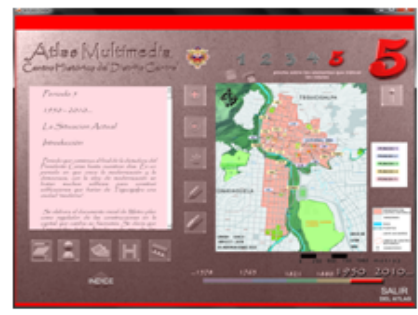

nombre:

fecha:

1. ¿qué es lo que miras en pantalla?

2. ¿qué es lo que más llama tu atención?

3. ¿qué está a la derecha? ¿y a la izquierda?

4. describe para qué piensas que sirve cada uno de los botones que están en la pantalla.

Se dejará que el usuario utilice el atlas hasta que se muestre que no lo desea utilizar más, entonces se le harán preguntas.

tiempo de uso:

5. ¿por qué dejaste de utilizarlo?

6. ¿qué es lo que más recuerdas del atlas?

7. ¿cuál es la edificación histórica que más recuerdas? y ¿por qué es importante?

8. ¿por qué es importante el centro histórico para ti?

9. ¿cuántas edificaciones históricas recuerdas? enuméralas.

10. como hondureño ¿por qué crees que se deben conservar estas edificaciones?

11. ¿crees que el atlas te enseñó a conocer el valor que tienen las edificaciones y el espacio del centro histórico? 
Figura 16. Proceso basado en el diseño basado en el usuario para probar ambos atlas

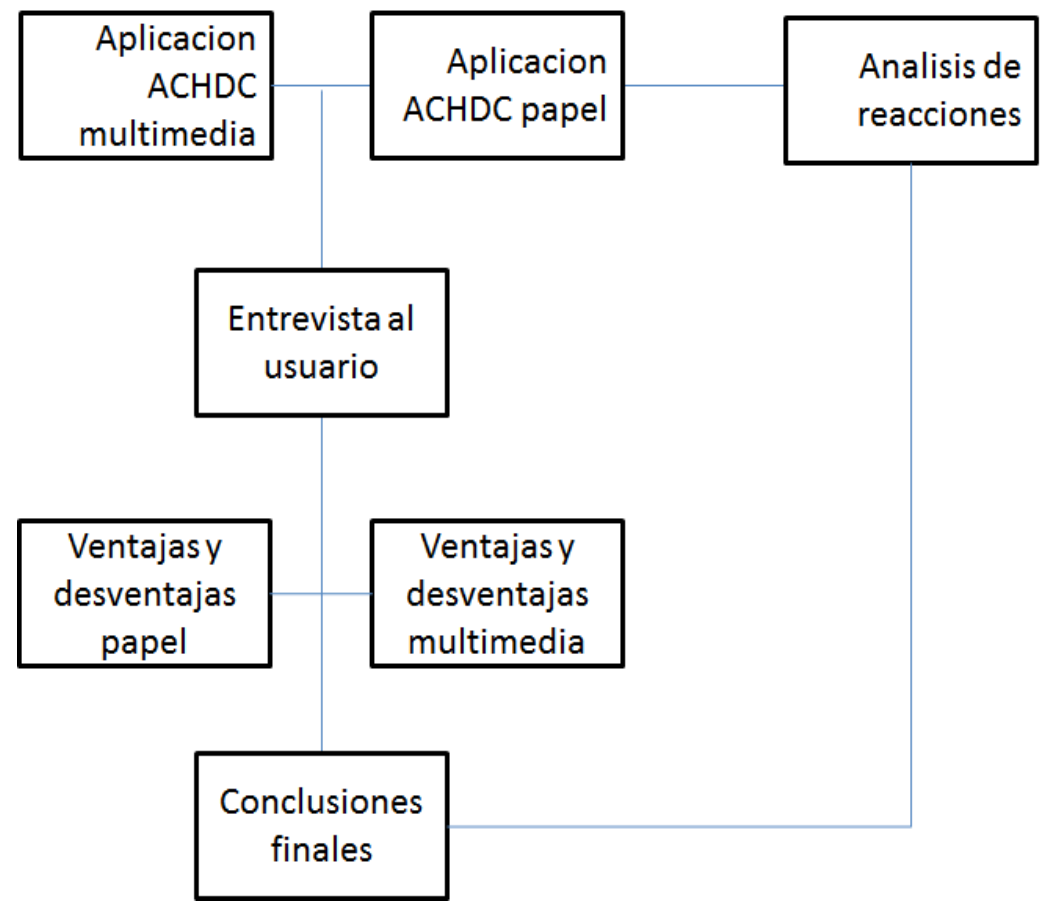

\section{ANÁLISIS DE LOS RESULTADOS OBTENIDOS}

Con la información obtenida se realizará un análisis de los resultados para ver y comparar las distintas reacciones de los entrevistados, viendo similitudes y diferencias. El estudio es de caso con enfoque etnográfico por la metodología. La entrevista que se realizará, espera analizar las reacciones del usuario con respecto al uso de ambos atlas, posteriormente se cuantificará quiénes y cuántos tuvieron un mejor aprovechamiento de cada recurso.

En una primera aplicación solamente de tipo experimental se notó que el usuario se toma más tiempo en utilizar el producto multimedia, por la mayor interactividad y capacidad de buscar opciones, es decir que al ver una variedad de enlaces a los que se puede optar hay más atracción y se mantiene más entretenido que con ver páginas (versión papel), que no nos llevan a ningún otro medio. 


\section{BIBLIOGRAFÍA}

- Adabala, Neeharika (2010). An interactive multimedia framework for digital heritage. Microsoft Research India. Scientia.

- Ardito, Carmelo (2010). Combining multimedia resources for an engaging experience of cultural heritage. Universidad de Bari, Departamento de Informática.

- Cartwright, William (2010). "Addressing the value of art in cartographic communication". Journal of Photogrammetry and Remote Sensing. ELSEVIER.

- Cartwright, William. (2007). Multimedia Cartography. New York: Springer Editorial.

- Stefanakis, Emmanuel, Peterson, Michael (2006). Geographic Hypermedia, Concepts and Systems. Springer Berlin Heidelberg Editorial.

- Gómez, Pineda (2010). "Atlas multimedia del Centro Histórico del Distrito Central de Honduras". Revista de Posgrados, Universidad Nacional Autónoma de Honduras.

- Oberholzer, Clemens (2000). Visualization of change in the interactive multimedia atlas of Switzerland. Computers and Geosciences. ELSEVIER. 